\title{
The Linguistic Complexity of the English Learners’ Writing*
}

\author{
John Evar Strid \\ Northern Illinois University, Illinois, USA
}

\begin{abstract}
Based on previous research suggests that programs which are more supportive of English learners' (ELs) native language help them better acquire academic language and skills and that additional cognitive development allows more linguistically complex writing, this research study examines compositions of three groups of 15 th grade students, including one group of non-ELs and two groups of ELs enrolled in different types of programs for ELs in order to determine the linguistic complexity of their writing. The research found that ELs who were in a program more supportive of their home language wrote longer and more linguistically complex essays than those who were not and even showed signs of writing longer and more linguistically complex essays than non-ELs.
\end{abstract}

Keywords: bilingual education, English learners, English learners’ (ELs), elementary education, writing

\section{Introduction and Literature Review}

Students who arrive at school and do not speak English face many issues in acquiring the academic skills necessary for success in United States (US) schools, meaning that their academic attainment lags behind students who arrive at school already speaking English. Much of the cause of this general delay in academic attainment relates to language skills, although other factors may play a role. In particular, English learners (ELs) need to master both the everyday social form of their new language as well as its special discourse necessary for success in school. As has long been noted, school age ELs are much quicker in acquiring social conversational skills - generally within two years, whereas the academic skills of ELs take five to seven years to approach grade norms (Cummins, 1984). Academic language is a special variety of English that is much more complex than everyday language and demands more time for mastery for ELs (Wilkinson \& Silliman, 2012). Because of the differences in terms of language characteristics and speed of acquisition, Cummins (1984) labeled the social variety as basic intercommunicative skills (BICS) and the academic form as cognitive/academic language proficiency (CALP). In general, academic language has a more difficult and less frequent lexicon, more complex syntax, and more formal discourse patterns (Baily, Butler, Stevens, \& Lord, 2007). In addition to being more cognitively demanding in terms of language characteristics in comparison to social language, Cummins (1984) also pointed out that academic language frequently has fewer contextual clues to support the ELLs in their acquisition of the novel forms.

The delay in the acquisition of academic language is commonly cited as a justification for bilingual education, allowing the ELs to continue their higher-level cognitive development through their home language

* Acknowledgements: Recognition needs to be given to the Center for the Interdisciplinary Study of Language \& Literacy at Northern Illinois University for a grant that permitted an additional coder, Sarah Eastlund, who helped analyze the essays. The administrators, teachers, and students at DeKalb Community Unit School District 428 and Elmwood Park Community Unit School District \#401 also merit recognition for agreeing to participate in the research.

John Evar Strid, Ph.D., assistant professor, Department of Literacy Education, College of Education, Northern Illinois University. 
while they are working on acquiring English in all of its forms. For example, Cummins (1984) made exactly this argument:

Spanish instruction that develops first language (L1) reading skills for Spanish-speaking students is not just developing Spanish skills: It is also developing a deeper conceptual and linguistic proficiency that is strongly related to the development of English literacy and general academic skills. (p. 22)

In comparison, English-only advocates argue that bilingual education delays acquisition of skills in English and have had some notable political success in limiting or banning bilingual education in several states like California, Arizona, and Massachusetts (Rossell \& Kuder, 2005). However, research looking at the early results of bilingual education in the initial grades has agreed that the program does not delay English literacy acquisition (Durán, Roseth, \& Hoffman, 2010; Slavin, Madden, Calderón, Chamberlain, \& Hennessy, 2011) and that existing empirical evidence indicates the superiority of the bilingual approach for overall educational attainment for language minority students (Slavin \& Cheung, 2005). In fact, available evidence indicates that programs that emphasize continued acquisition of both languages over the long term actually result in stronger English language skills than programs focused on transitioning to English. Overall, as ELs progress through school bilingual programs have helped them make greater academic progress than programs that exclusively use English (Francis, Lesaux, \& August, 2006) and bilingual programs of shorter duration and that emphasize rapid transitioning to English are less successful in allowing ELs to catch up and even surpass normal grade level test scores (Thomas \& Collier, 1997). In general, greater time to adjust to advanced language skills needed to master academics in the second language as well as continued development of the home language seems to help ELs the most and helps them make the most progress in developing increased metalinguistic awareness (Carlisle, Beeman, Davis, \& Spharim, 1999). In fact, bilingualism, in general, has been shown to give leaners gradually greater metalinguistic awareness over a period of five years of continued learning of both languages (Bialystok, Peets, \& Moreno, 2012).

The effect of greater overall language mastery afforded by greater support of the student's home language in longer duration bilingual programs while they are mastering a new language should be found in all language modalities, including listening, speaking, reading, and writing, the focus of this study. In some ways, writing is the most cognitively demanding of the four modalities, typically involving advanced planning and greater control to achieve the writer's intentions in communicating meaning to potential readers, forcing the writer to manipulate real world knowledge along with linguistic skills like knowledge of discourse patterns, lexical knowledge, and syntactic knowledge, as well as knowledge about potential readers (Perfetti \& McCutchen, 1987).

As students progress through school, their writing skills develop on numerous levels, leading to the production of texts of greater complexity. The increased quality of writing corresponds with increases in underlying skills, starting with lower level skills (like motor control and phoneme segmentation) in the lower grades (Abbott, Berninger, \& Fayol, 2010; Berninger et al., 1994; Berninger et al., 1992) and moving into higher level skills in the higher grades and in adult writers (like executive control and greater working memory) (Berninger, Fuller, \& Whitaker, 1996; Berninger et al., 2010; Perfetti \& McCutchen, 1987). The increase in older, more experienced writers' underlying cognitive abilities allows them to attend to additional textual features, such as coherence and cohesion using increasing complex syntax to relate ideas and planning and revising to ensure the piece's interpretation by the reader (McCutchen, 1986; Perfetti \& McCutchen, 1987). 
ELs who are in the process of mastering writing in an additional language should see the same progression of cognitive skills, thereby, allowing them to increase the complexity of their writing. Also, many writing skills developed in their home language should transfer into their new language. As noted in a report by the National Literacy Panel, "Research on the development of writing skills in English-language learners is extremely sparse, and research on cross-linguistics influences in the acquisition of writing skills by English language learners is even more sparse” (Genesee, Geva, Dressler, \& Kamil, 2006, p. 169). What little empirical evidence exists does suggest that native language writing skills support writing in the additional language. For example, Edelsky (1982) investigated the native and additional language writing of 1st, 2nd, and 3rd graders in a bilingual program, finding that knowledge of writing in the native language aided writing in English, allowing knowledge of the writing process, writing conventions, etc.. Lanauze and Snow (1989) examined the writing of 4th and 5th graders in a Spanish-English bilingual program for linguistic complexity, linguistic variety, and semantic content, finding that only the linguistic variety ratings demonstrated significant cross-linguistic influence and only for writers rated as having high proficiency in Spanish and low in English, suggesting that mastery of skills in one language can be recruited into the other language (and that these writers did so). In an additional study of bilingual children in the first three grades learning literacy in English, Davis, Carlisle, and Beeman (1999) found transfer from English to Spanish, with writing in English (the language of instruction) between the 1st and 2nd grades and with improvements transferring to Spanish (the uninstructed native language) in the 3rd grade. Similarly, Francis (2000) found transfer from a language of instructed literacy (Spanish) to a non-instructed native language (Náhuatl) in the writing of 3rd and 5th grade bilinguals, but that Náhuatl also influenced their writing in Spanish through cross linguistic influence or interlanguage. In a longitudinal study of Dutch, secondary students learning to write in English as a foreign language, Schoonen et al. (2011) found a strong relationship between native and additional language writing ability through modeling and that additional language writing correlated even more strongly with linguistics knowledge and fluency than native language writing. Finally, studying adults writing in an additional language, Cumming (1989) found that both writing expertise and additional language proficiency explained the quality of written texts, with writing expertise contributing to the organization of discourse and content and additional language proficiency adding to the overall quality of writing without affecting the discourse organization.

In summary, all relevant studies to date of writers learning their craft in an additional language argues for the facilitative nature of knowledge of writing even when acquired in a native language different from the target language. The present research examines the English writing of ELs who have received services using different program approaches (maintenance Spanish-English bilingual program compared to English immersion with pullout English as a second language [ESL] support) to determine if a difference exists in the overall quality of their writing in English. The study started with the hypothesis that a program more supportive of the native language, allowing the EL additional time to work on cognitive skills and to increase their skills in both languages, thereby, supporting bilingualism and metalinguistic awareness, would result in qualitatively better writing in terms of linguistic complexity.

\section{Method}

\section{Subjects}

Three groups composed of 14 5th grade students were recruited from school districts in Northern Illinois. The school districts were selected for their similarities in terms of demographics, but also for their differences 
in program type for instructing ELs. One group of ELs came from a district that gave students support in both English and Spanish, teaching literacy skills in both languages in a maintenance bilingual program. Another group of ELs were enrolled in a district that immersed them in regular English speaking classrooms, while offering them additional help to learn English with ESL pullout support services. The control group came from the same school district as the ELs receiving pullout ESL and was composed of non-ELs who came to school speaking English as their primary language and did not receive any language support services of any kind. To control for socio-economic status, all participants qualified for the school lunch program. All participants had stayed in the same school district from the beginning of their education. All EL participants came from Spanish-speaking backgrounds.

\section{Design and Materials}

An English writing sample was collected from all participants, in a controlled manner in the different schools, with the same writing prompt. Coordination with cooperating teachers in both school districts ensured the use of the same writing prompt in similar contexts and with identical time and instructional requirements. All teachers received instructions asking them to give the 5th grade participants the following prompt with the same pre-teaching activity and allowing the same amount of writing time:

\section{Fifth Grade Narrative Writing Prompt}

Write about a time you experienced or learned something for the first time. It could be when you first rode a bike or learned a new game. It could have been your first day of school, your first train or plane ride, or your first trip to an amusement park. First experiences are special for some reason. They may be funny, scary, or exciting. Be sure and give your narrative a clear beginning, middle, and end, with details in the proper order.

The resulting writing sample was examined for linguistic complexity using various measures, including number of words, number of $t$ units (Hunt, 1977), mean length of $t$ unit, number of noun phrases (NPs), percentage of NPs that were pronominal, number of NPs per $t$ unit, number of subject NPs, number of words per verb phrase, number of words per verb complex, use of organizational and transitional words and phrases, and use of non-finite constructions. Sophistication of vocabulary was established by comparing the frequencies of nouns, verbs, and adjectives using SUBTLEXus database (Brysbaert \& New, 2015). Tracking the use of organizational words and transitional phrases compared the cohesion and organization of the essays. All essays were examined by two coders, who independently analyzed each essay before entering into discussion to come to consensus on the final analysis.

\section{Results}

The narrative writing prompt yielded 42 essays on a limited variety of topics, with two main strands of responses. The most essays (18) concerned a trip, with seven of them centering on a first airplane trip, including two about trips to Florida, one to California, one to Europe, and three without a stated destination. An additional seven essays concerning trips recounted outings to amusement parks, including two essays about water parks in the Wisconsin Dells and three with a destination of Six Flags. An additional travel essay discussed when the writer migrated to the US, another concerned a trip to Mexico and two more were about outings to Chicago. The second most common topic from the prompt was about learning a skill, including five essays about learning to ride a bicycle, four about learning to play an instrument or sing, three about learning to play soccer, two about learning to rollerblade or skate, one about cheerleading, and one about competing in 
karate. Six essays concerned a first day at school, two essays were about how the author learned to fear dogs and the remaining essay told the story of a fire drill.

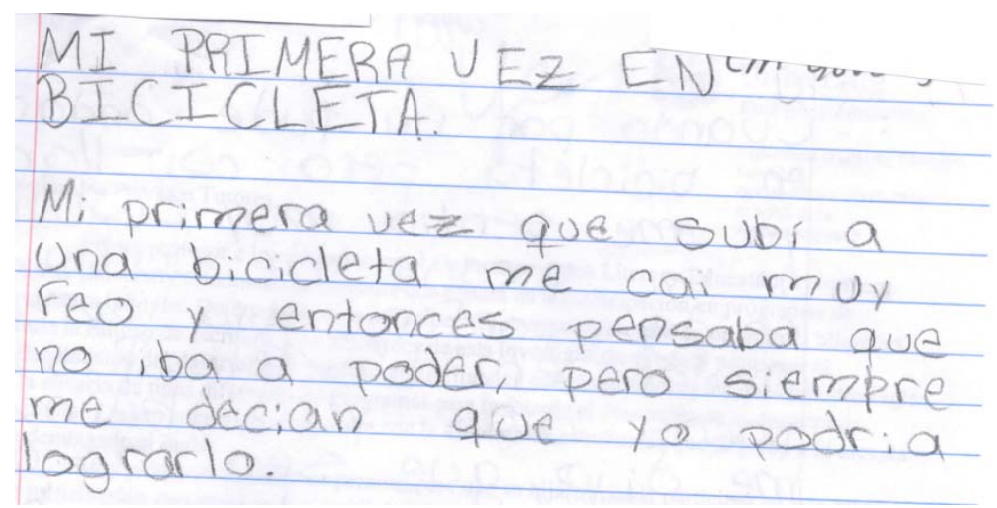

Figure 1. A part of participant 4's 167 word essay in clear Spanish.

Two essays were excluded from complete analysis. The first was excluded from the ESL group, because participant four had composed an essay of 167 words in well-written Spanish instead of English (see Figure 1). An additional essay of 72 words from the maintenance group was also removed from analysis despite being written in English, because it used Spanish phonics and ultimately the two coders could not agree on what the actual words were in the essay (see Figure 2). The exclusion of two essays meant that 40 essays were included in the analysis, with 13 essays from ELs in maintenance, 13 from ELs in pullout ESL, and 14 from non-ELs.

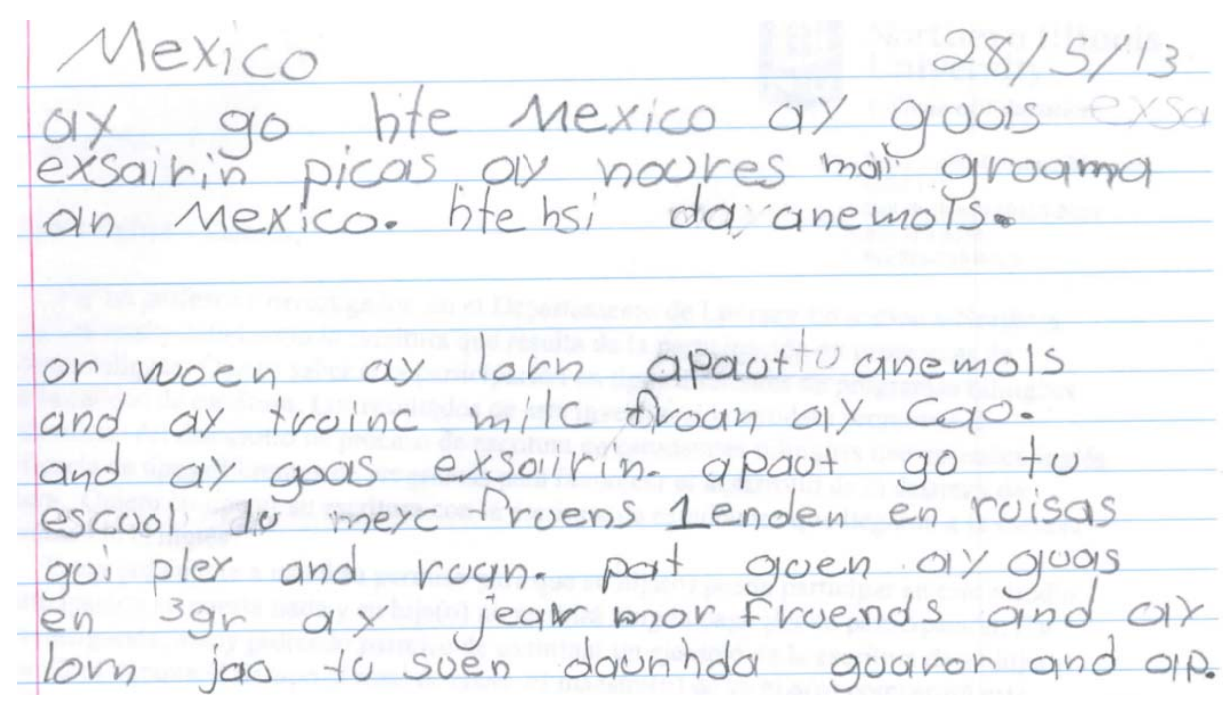

Figure 2. Subject 35's 72 word essay in Spanish influenced English.

Statistical comparisons of the different factors outlined above to measure linguistic complexity of the essays showed that the three different groups differed in many of them (see Table 1). Starting the analysis with one-way ANOVAs (Non-EL $\times$ ESL $\times$ Maintenance) comparing all three groups, they demonstrated that the groups differed significantly in eight of 17 categories of analysis (discussed in depth below). Following up, $t$-tests more directly compared the different subject groups in order to further clarify the differences between each of the groups, the results of which are also discussed in depth below. In general, comparing the ELs who received ESL pullout services with the control group of non-ELs demonstrated little difference between their 
essays, while the maintenance group differed significantly on many measures from both the ESL pullout group and the non-EL groups. Finally, statistical testing using the $\chi^{2}$ test to examine the percentage of noun phrases that were pronouns or subject demonstrated no significant differences between groups.

Table 1

Summary of Statistical Comparisons Between Groups

\begin{tabular}{|c|c|c|c|c|c|c|c|c|c|c|c|}
\hline & \multirow{2}{*}{\multicolumn{3}{|c|}{ Group }} & \multicolumn{8}{|c|}{ Tests of signficance } \\
\hline & & & & & & & & \multicolumn{2}{|c|}{$T$-tests } & & \\
\hline & \multirow{2}{*}{ Non-EL } & \multirow{2}{*}{ ESL } & \multirow{2}{*}{ Maintenance } & \multicolumn{2}{|l|}{ ANOVAs } & \multicolumn{2}{|c|}{ Non-EL/ESL } & ESL/I & Maint & \multicolumn{2}{|c|}{ Non-EL/Maint } \\
\hline & & & & \multicolumn{2}{|l|}{$F(2,37)$} & \multicolumn{2}{|c|}{$t(24-25)$} & \multicolumn{2}{|c|}{$t(24-25)$} & \multicolumn{2}{|c|}{$t(24-25)$} \\
\hline \# Words & 156.857 & 144.65 & 263.885 & 11.066 & 0.000 & 0.488 & 0.630 & -4.235 & 0.000 & -3.608 & 0.001 \\
\hline \# T-Units & 16.43 & 16.38 & 34.54 & 5.471 & 0.008 & 0.014 & 0.989 & -3.011 & 0.006 & -2.607 & 0.015 \\
\hline Avg $T$-unit length & 12.88 & 9.09 & 10.47 & 1.118 & 0.338 & 1.237 & 0.228 & -1.638 & 0.115 & 0.781 & 0.442 \\
\hline SD Avg $T$-unit length & 3.82 & 4.01 & 5.05 & 3.324 & 0.047 & -0.394 & 0.697 & -2.164 & 0.041 & -2.127 & 0.043 \\
\hline Avg NP/T-unit & 3.81 & 2.88 & 3.39 & 1.167 & 0.323 & 1.312 & 0.201 & -1.781 & 0.088 & 0.573 & 0.572 \\
\hline SD Avg NP/T-unit & 1.36 & 1.32 & 1.82 & 4.623 & 0.016 & 0.243 & 0.810 & -2.9 & 0.008 & -2.287 & 0.031 \\
\hline \# NP & 50 & 45.54 & 85.54 & 11.713 & 0.000 & 0.551 & 0.586 & -4.403 & 0.000 & -3.366 & 0.001 \\
\hline \# NP Pro & 23.86 & 22.62 & 39.77 & 9.927 & 0.000 & 0.306 & 0.762 & -3.948 & 0.001 & -3.633 & 0.001 \\
\hline \# Subj NP & 24.86 & 23.62 & 40.85 & 8.959 & 0.001 & 0.304 & 0.764 & -3.799 & 0.001 & -3.285 & 0.003 \\
\hline Avg Words VP & 7.88 & 6.1 & 7.4 & 1.63 & 0.210 & 1.566 & 0.130 & -2.086 & 0.048 & 0.405 & 0.689 \\
\hline SD Avg Words VP & 4.62 & 3.65 & 4.53 & 1.201 & 0.312 & 1.305 & 0.204 & -1.938 & 0.064 & 0.116 & 0.909 \\
\hline Avg Word/Verb & 1.26 & 1.24 & 1.32 & 1.176 & 0.320 & 0.398 & 0.694 & -1.53 & 0.139 & -1.075 & 0.293 \\
\hline SD Avg Word/Verb & 0.58 & 0.5 & 0.62 & 1.558 & 0.224 & 1.13 & 0.269 & -1.947 & 0.063 & -0.503 & 0.619 \\
\hline Avg Freq N,V,ADJ & 60354.02 & 70560.91 & 62249.07 & 2.068 & 0.141 & -1.889 & 0.071 & 1.531 & 0.139 & -0.368 & 0.716 \\
\hline SD Avg Freq & 98663.68 & 103848.25 & 94962.58 & 0.983 & 0.384 & -0.834 & 0.412 & 1.395 & 0.176 & 0.589 & 0.561 \\
\hline \# Org \& Trans & 5.57 & 5.08 & 7.08 & 1.058 & 0.357 & 0.315 & 0.755 & -1.884 & 0.072 & -0.977 & 0.338 \\
\hline \multirow[t]{2}{*}{ Non-finite } & 4.21 & 4.15 & 7 & 3.614 & 0.037 & 0.054 & 0.957 & -2.377 & 0.026 & -2.175 & 0.039 \\
\hline & & & & Key & & \multicolumn{6}{|c|}{ Chi-square tests $\chi^{2}(1)$} \\
\hline$\%$ NP Pro & 48.48 & 49.55 & 46.87 & \multirow{2}{*}{\multicolumn{2}{|c|}{$\begin{array}{l}\text { Significant } \\
\text { Approaching } \\
\text { Signficance }\end{array}$}} & 0.08 & 0.777 & 0.18 & 0.671 & 0.02 & 0.887 \\
\hline \% Subj NP & 49.50 & 52.23 & 47.71 & & & 0.08 & 0.777 & 0.32 & 0.572 & 0.08 & 0.777 \\
\hline
\end{tabular}

\section{Essay Length}

Clearly, the maintenance group wrote longer essays in the time allotted than the other groups, averaging 264 words per essay in comparison to 145 for the ESL group and 157 for the non-ELs as demonstrated in Figure 3. The one-way ANOVA comparing groups was significant $(F(2,37)=11.066, p=0.000)$. The difference was confirmed by $t$-tests, with the essays written by the maintenance subjects having significantly more words than those written by the ESL pullout subjects $(t(24)=-4.235, p=0.000)$ and those written by the control group of non-ELs $(t(25)=-3.608, p=0.001)$. Subject 37 in the maintenance group wrote the longest essay with 435 words on two pages (see Figure 4).

The maintenance group also wrote more $T$-units than both the other groups, averaging $34.53 T$-units per essay in comparison to 9.77 for the ESL group and 20.57 for the non-EL group. The one way ANOVA showed significance $(F(2,37)=5.471, p=0.008)$. The maintenance group's number of $T$-units was significantly greater than the ESL group's $(t(24)=-3.011, p=0.006)$ and the non-EL group's $(t(25)=-2.607, p=0.015)$. In fact, the number of words was highly correlated with $T$-units, with a coefficient of correlation of $r^{2}=0.780$ (see Figure 5). 


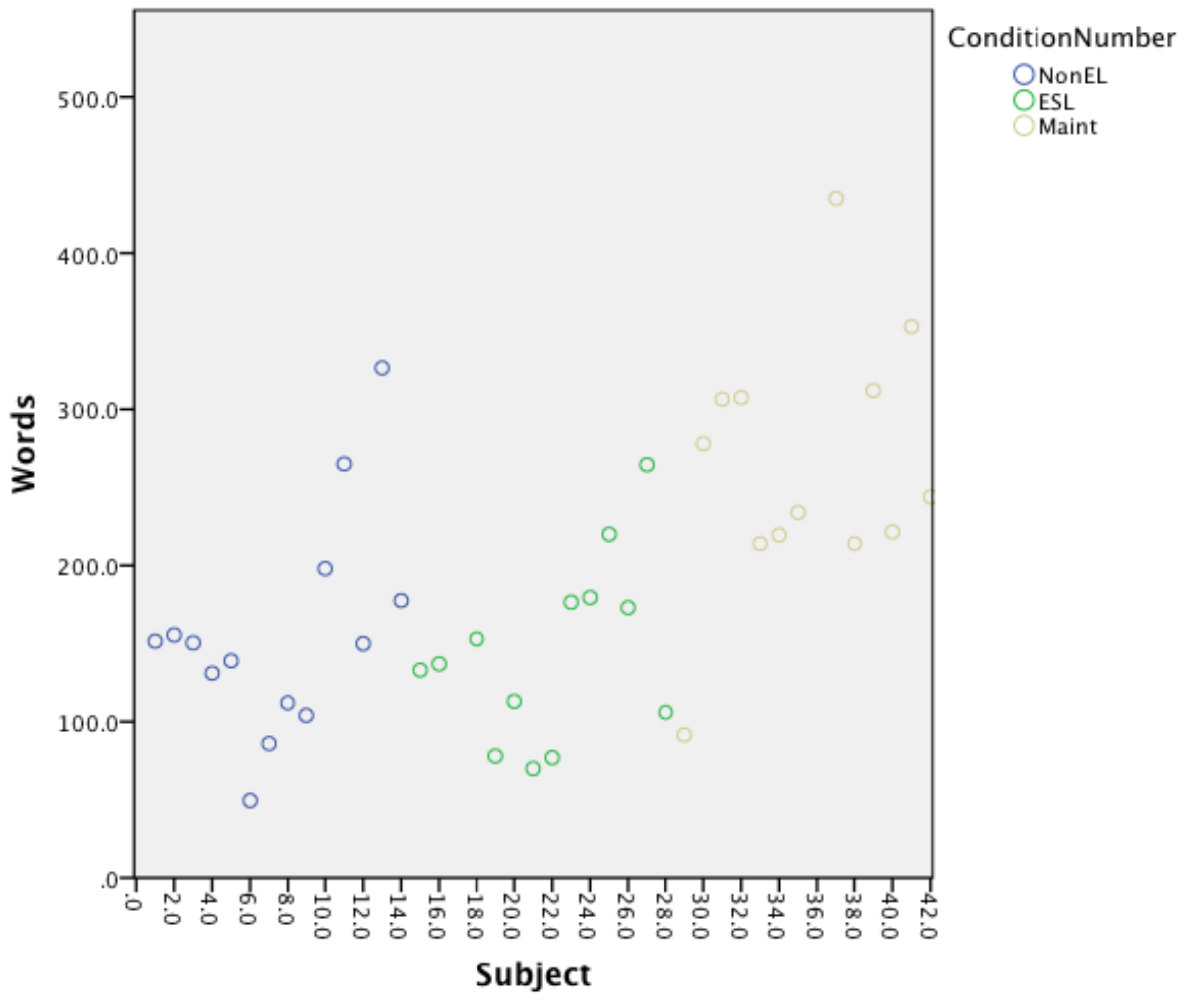

Figure 3. Lengths of the different essays.

When I first went to Mt. Olumpus.

When I first went to Wisconsin dells Mt Ulympus it was a really great aperience. I hod always wanted to go to an Amusment park and I finnaly get a chance to.

My mom's friend tad invited us to golI was really arred and I could not wat for the big day to comel Finally it had comend, since it was a 3 hour drive we took some water bottles and snocv's just in case we got hungry. It felt mare than a 3 har onve. My sister fell asleep I wos tired to but I did not want to miss all the pretty vews we pooset by a lot of other amusmert parks like yoggi bear and other one's. Tithen in a biboard you could see It said wacome To Mt. Olymplo!

Figure 4. The first two paragraphs of subject 37's 435 word, two page essay. 


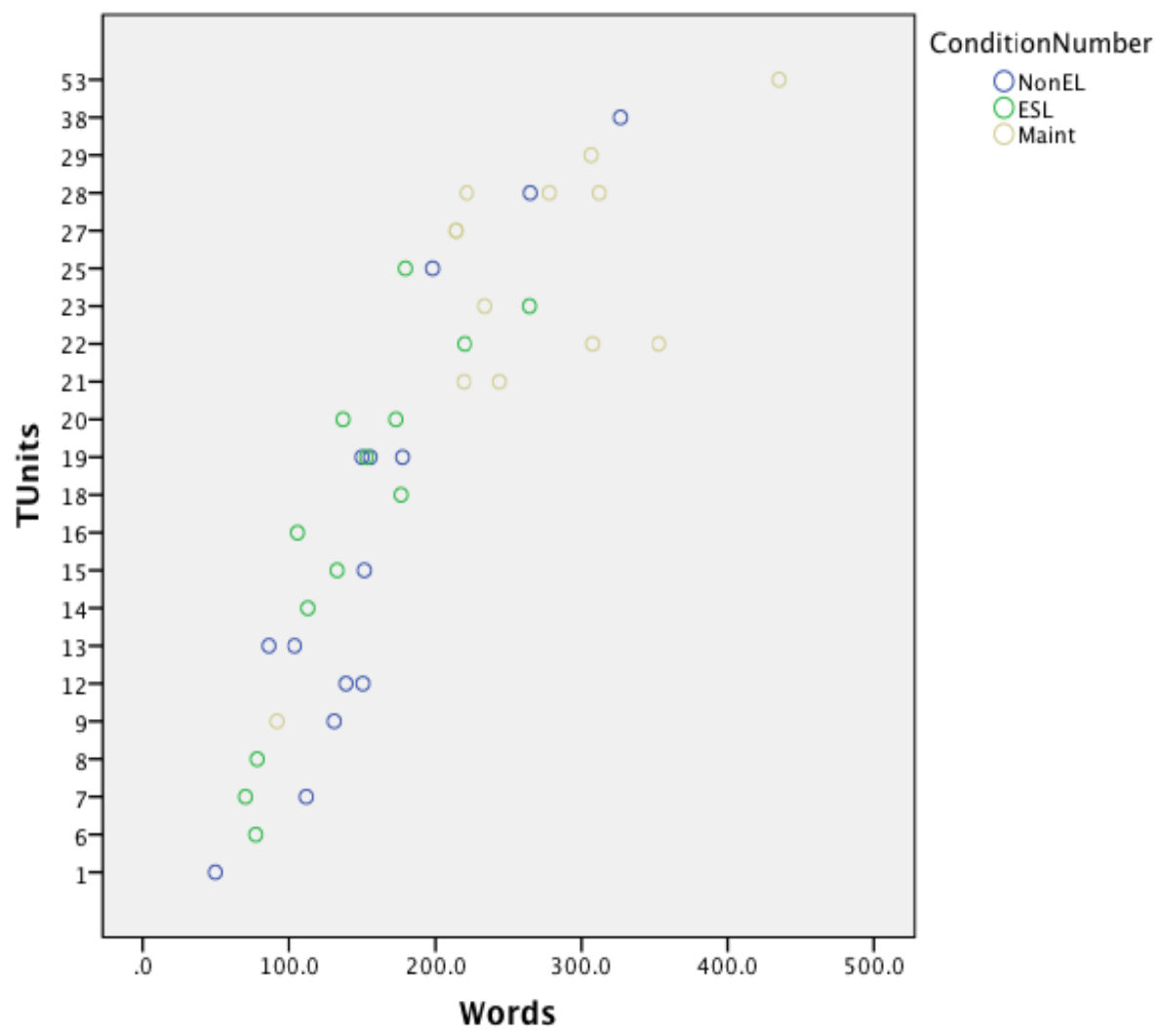

Figure 5. Correlation between the number of words and T-units.

As noted in Table 1, the different groups did not differ statistically in the average length of $T$-units, with ESL pullout averaging 9.09 words per T-unit, maintenance averaging 10.47, and non-EL 12.88. However, it is interesting to note that subject 6 in the non-EL group wrote a 49.5 word essay consisting of one $T$-unit, a clear outlier (see Figure 6). It is also the shortest essay of the entire sample in terms of the number of words. Repeated discussion between both coders failed to divide it into separate $T$-units.

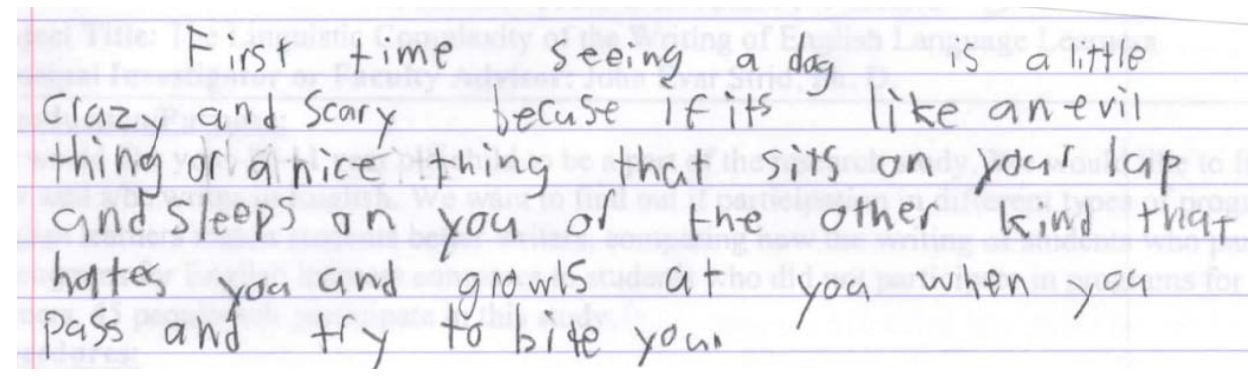

Figure 6. Subject 6 (Non-EL): 49.50 words in one T-unit.

For the standard deviation of the average $T$-unit length, the maintenance group showed the greatest variation with 5.05 compared to 4.01 for the pullout ESL group and 3.82 for the non-EL group. The difference between groups was statistically significant according to the one way $\operatorname{ANOVA}(F(2,37)=3.324, p=0.047)$. According to $t$-tests, the difference between the maintenance and the ESL pullout groups was statistically significant $(t(24)=-2.164, p=0.041)$ and also between the maintenance and the non-EL groups $(t(25)=-2.127$, 
$p=0.043$ ). Subject 41 (maintenance) had the most variation in $T$-unit length, with a $S D$ of 8.02 and varying from 5 to 41.5 words (the second longest $T$-unit after subject 6's $1 T$-unit 49.5 word essay seen previously. Subject 41's essay had 353 words, with $22 T$-units with an average $T$-unit length of 16.05 (see Figure 7).

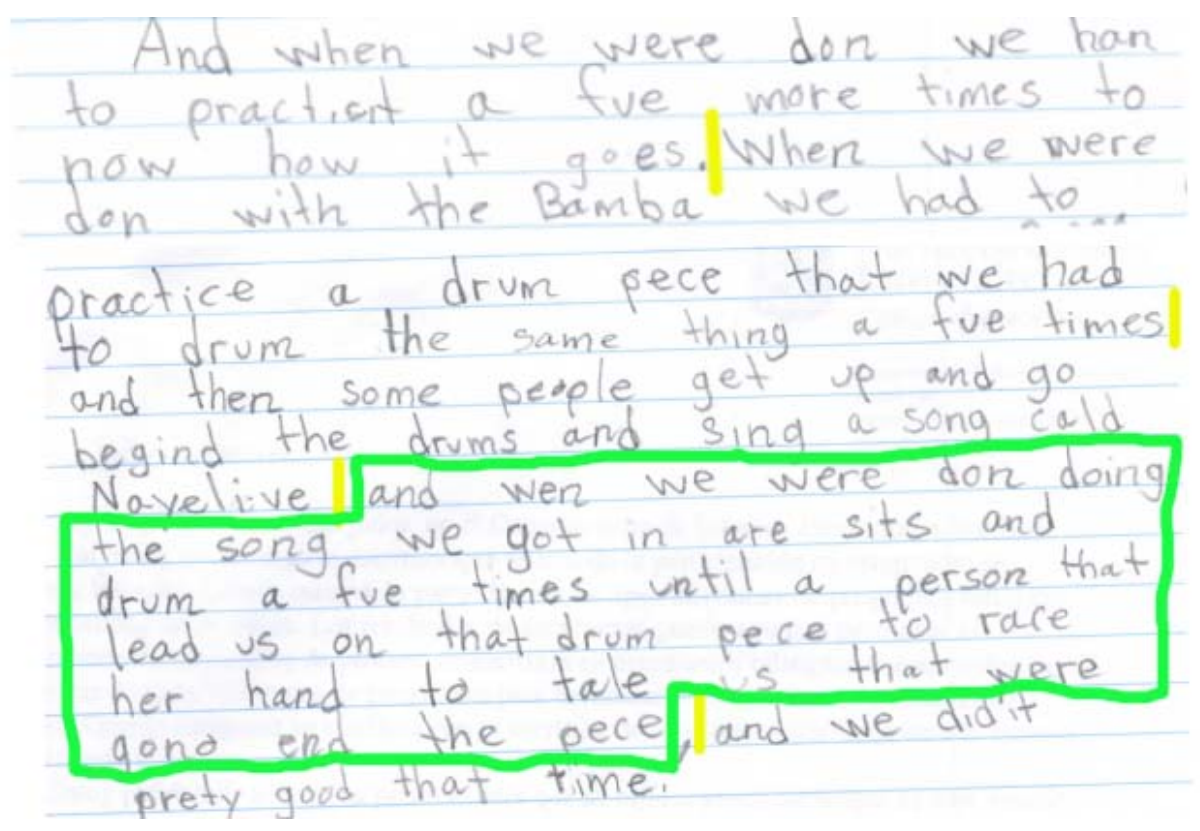

Figure 7. Subject 41's really long $T$-unit.

\section{Noun Phrases}

For the number of noun phrase per T-unit the maintenance group averaged 3.39, the ESL pullout group 2.88, and the non-ELs 3.81, a difference between groups that was not statistically significant either according to the one way ANOVA or the independent samples $t$-tests. However, the difference between the maintenance and ESL pullout groups approached significance in $(t(24)=-1.781, p=0.088)$. Also, the standard deviation in the average number of noun phrases in $T$-units saw the maintenance group average 1.82, the ESL pullout 1.32, and the non-EL 1.36. The difference between groups was significant according to the ANOVA $(F(2,37)=4.623, p$ $=0.016)$. From the $t$-tests, the significant differences were found between the maintenance and the ESL pullout groups $(t(24)=-2.9, p=0.008)$ and the maintenance and non-EL groups $(t(25)=-2.287, p=0.031)$. Subject 32 (maintenance) had the highest $S D$ of average number of NPs in $T$-units, with 307.5 words divided in $22 T$-units, with an average number of NPs of 5 and a $S D$ of 2.92 (see Figure 8).

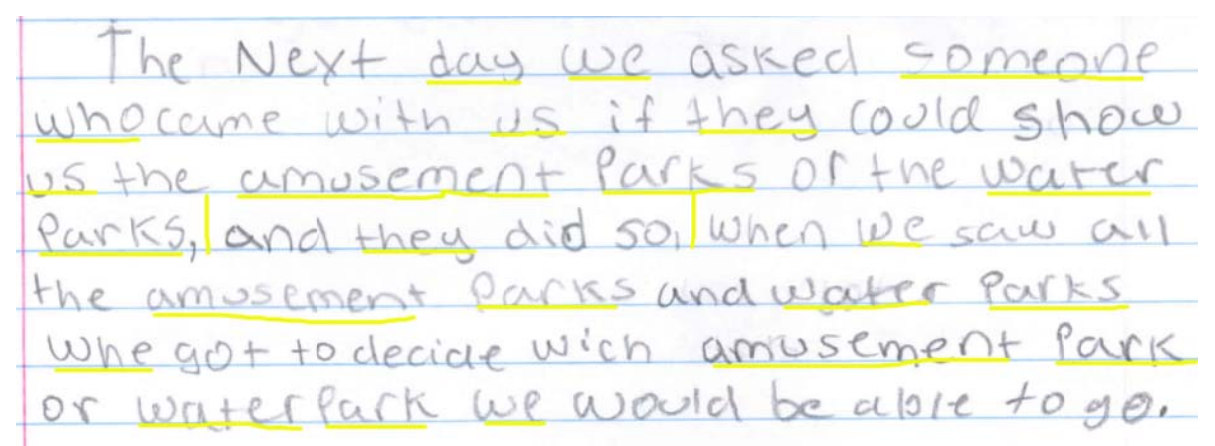

Figure 8. Three T-units from subject 32's essay (maintenance). The first one has $11 \mathrm{NPs}$, the second has one, and the last 11 again. 
Considering the overall measure of noun use, the number of noun phrases in the essays, the non-EL group averaged 50, the ESL pullout 45.54, and the maintenance 85.54. According to the one-way ANOVA, the differences between groups was statistically significant $(F(2,37-39)=11.713, p=0.000)$. According to independent samples $t$-tests, the maintenance group wrote significantly more noun phrases than the ESL group $(t(24)=-4.403, p=0.000)$, and the non-EL group $(t(25)=-3.366, p=0.001)$. Subject 36 (maintenance) had the most NPs (as well as most words and most $T$-units), with 140 NPs (out of 435 words). The number of words was highly correlated with the number of NPs, with a coefficient of correlation of $r^{2}=0.976$ (see Figure 9).

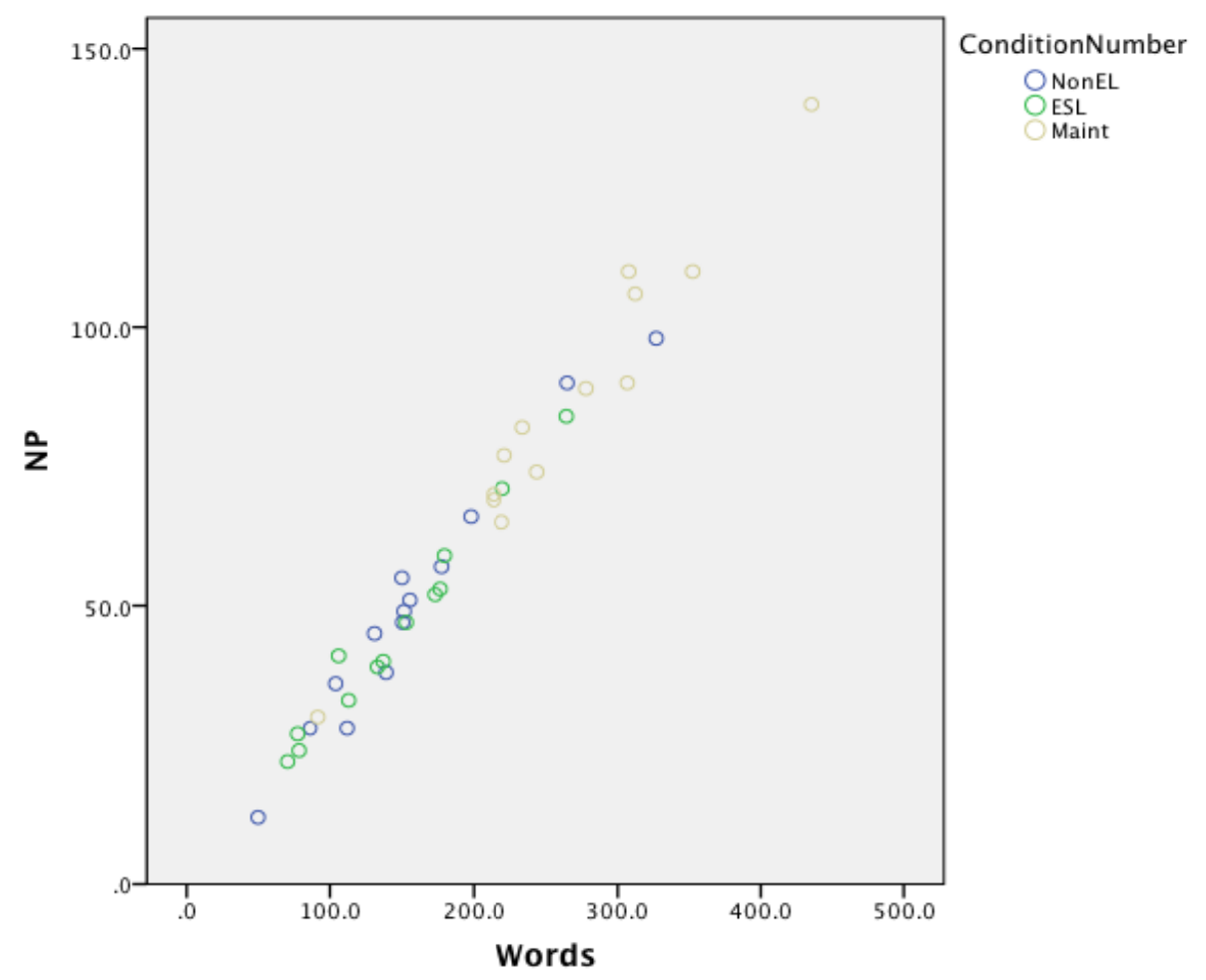

Figure 9. Correlation between the number of words and noun phrases.

The other measures concerning nouns patterned similarly to the statistics for the overall number of noun phrases. First, the non-EL group wrote an average of 23.86 pronouns as noun phrases in comparison to the ESL pullout group with 22.62 and the maintenance group with 39.77. As with the previous, this difference was statistically significant between groups according to a one-way ANOVA $(F(2,37)=9.927, p=0.000)$. Once again, the maintenance group used more pronouns as noun phrases than the ESL pullout group $(t(24)=-3.948$, $p=0.001)$ and the non-EL Group $(t(25)=-3.633, p=0.001)$. Next, the non-EL group wrote an average of 24.86 subject noun phrases, the pullout ESL group 23.62, and the maintenance 40.85 in their essays. In the same pattern as the previous, the one-way ANOVA showed that the groups differed significantly $(F(2,37)=8.959$, $p=0.001)$. The independent samples $t$-tests showed that the maintenance group wrote more subject noun phrases than the ESL pullout group $(t(24)=-3.799, p=0.001)$, and the non-EL group $(t(25)=-3.285, p=0.003)$. Verbs

Turning to measure involving verbs, for the first measure, the number of words per verb phrase, the non-EL group averaged 7.88, the ESL pullout 6.1, and the maintenance 7.4. This was statistically significant only for the difference between the maintenance and the ESL pullout groups according to the independent 
samples $t$-test $(t(24)=-2.086, p=0.048)$. For the standard deviation of the average number of words per verb phrase, the three groups were also fairly similar with the non-EL group averaging 4.62, the ESL pullout 3.65, and the maintenance 4.53, a difference between groups that only approached significance for the maintenance and ESL pullout groups $(t(23)=-1.938, p=0.064)$. For the measure of the average words per verb (meant to count more complex verb and tense constructions), the three groups did not test as statistically different with the non-EL group averaging 1.26, the ESL pullout 1.24, and the maintenance 1.32. The standard deviation of the average number of words per verb complex was also similar across groups with the non-ESL group averaging 0.58 , the ESL pullout 0.5 , and the maintenance 0.62 . This difference only approached statistical significance between the maintenance and the ESL pullout groups $(t(24)=-1.947, p=0.063)$.

Turning to the use of non-finite constructions, the non-EL group averaged 4.21, and the ESL pullout group 4.15, and the maintenance group 7.0. The differences between groups was statistically significant according to the one-way ANOVA $(F(2,37)=3.614, p=0.037)$. Breaking out the differences using independent samples $t$-tests revealed that the differences were significant between the maintenance and ESL pullout groups $(t(24)=$ -2.377, $p=0.026)$ and the maintenance and non-EL groups $(t(25)=-2.175, p=0.039)$. Subject 41 , with an essay on playing an instrument, had the most with 13. In fact, in this excerpt, the writer used six non-finite constructions (see Figure 10).

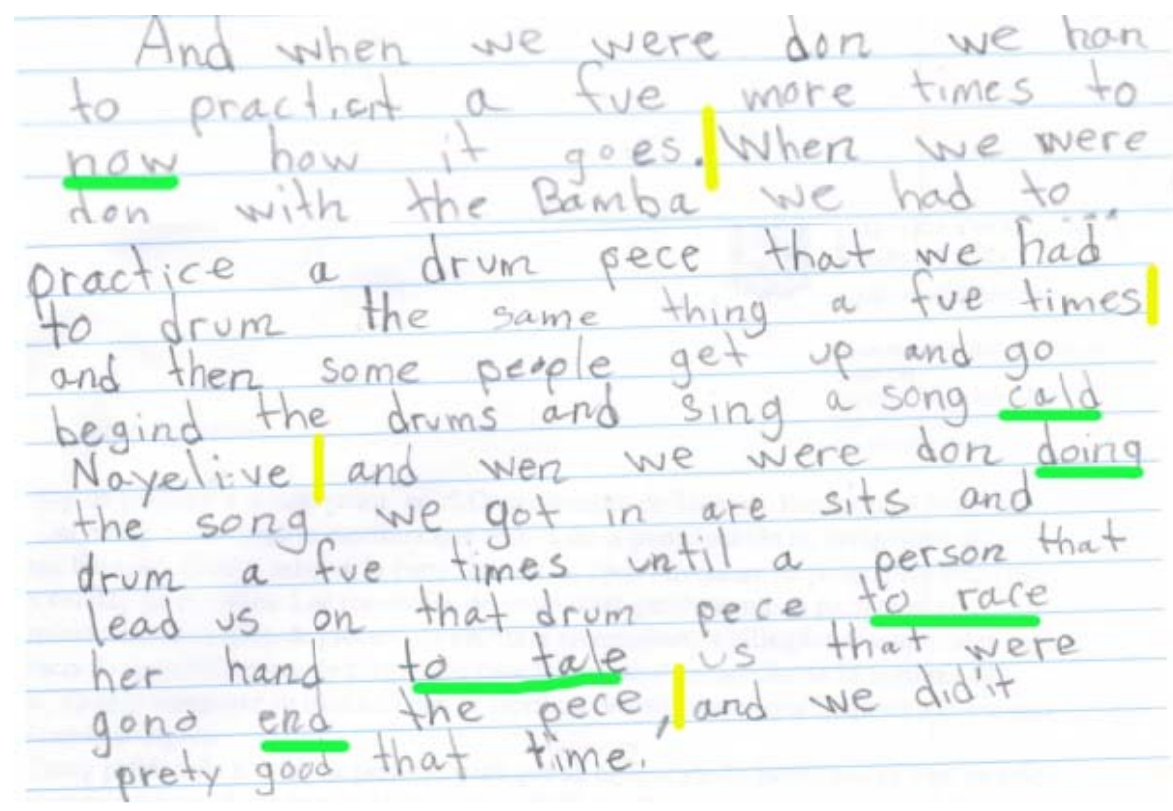

Figure 10. Subject 41's 6 non-finite verbs (underlined in green) in $5 T$-units.

Only a few other factors of complexity even approached significance. For the average frequency of nouns, verbs, and adjectives, the pullout ESL essay writers tended to employ words of higher frequency than the non-EL essayists, a difference approaching statistical significance according to the independent samples $t$-test $(t(25)=-1.889, p=0.071)$. Additionally, the maintenance group approached statistically significant greater use of organizational and transition words than the ESL pullout group $(t(24)=-1.884, p=0.072)$.

\section{Discussion and Conclusion}

The pattern of results indicates that the EL participants in a maintenance bilingual program wrote longer 
and more linguistically complex essays than EL participants in a pullout ESL model. The maintenance group wrote more significantly words, more T-units, more NPs (all correlated) than both ESL and non-EL groups. They also wrote significantly more pronouns and NP subjects, had significantly more average words in verb phrsase than ESL group, used non-finite constructions significantly more than both ESL and non-EL groups, and trended toward significantly more organizational and transitional words and phrases than the ESL group. The maintenance group writers also showed signs of greater variation in writing by having significantly higher variation in average $T$-unit length $(S D)$ than ESL and non-EL groups having significantly higher variation in average of NPs per T-unit (SD) than ESL and non-EL groups and trending to significantly more variation in average words in VP and average words per verb than ESL group.

The results of this experiment provide additional evidence that programs that are more supportive of ELs' L1 also help them acquire better writing skills in English. The findings, in fact, argue that this model best supports English development in all language modalities since writing is commonly viewed as the hardest modality (Perfetti \& McCutchen, 1987). The results revalidate Cummins (1984) conception that learning in the L1 transfers to the second language (L2). It also agrees with much research that has found longer duration bilingual programs superior in allowing ELs to achieve academic success (Slavin \& Cheung, 2005; Francis et al., 2006; Goldenberg, 2008; Thomas \& Collier, 1997). In general, the findings suggest that bilingual programs of longer duration better allow ELLs to acquire the academic language of school, in addition to the cognitive benefits of bilingualism (Carlisle et al., 1999; Bialystock et al., 2012).

In particular, these results are significant in examining EL attainment based on the services they received in the understudied area of writing, which as the most cognitively demanding modality serves as a good reference of overall language skills. By examining their writing skills in the L2, which all participants have been working on in the different programs type, the results suggest that learning to write in the native language is supportive of learning to write in the new language, agreeing with previous research finding a facilitative effect (Davis et al., 1999; Francis, 2000; Shoonen et al., 2011; Cumming, 1989). In general, the results support approaches to teaching ELs that view their home language as a resource that can be further developed and used to aid learning English.

Additional research is needed to determine the degree of advantage by maintenance program participants and how their writing compares to EL learners who receive additional kinds of services, as well as to additional non-English learner control participants. A future direction for follow-up research needs to be the identification of additional measures of linguistic complexity that do not correlate with one another.

\section{References}

Abbott, R., Berninger, V., \& Fayol, M. (2010). Longitudinal relationships of levels of language in writing and between writing and reading in Grades 1 to 7. Journal of Educational Psychology, 102, 281-298. doi: 10.1037/a0019318

Baily, A. L., Butler, F. A., Stevens, R., \& Lord, C. (2007). Further specifying the language demands of school. In A. L. Baily (Ed.), The language demands for school (pp. 103-156). New Haven, C.T.: Yale University Press.

Berninger, V. W., Cartwright, A. C., Yates, C. M., Swanson, H. L., \& Abbott, R. D. (1994). Developmental skills related to writing and reading acquisition in the intermediate grades: Shared and unique functional systems. Reading and Writing, 6, 161-196. doi: 10.1007/BF01026911

Berninger, V. W., Fuller, F., \& Whitaker, D. (1996). A process model of writing development across the life span. Educational Psychology Review, 8, 193-218. doi: 10.1007/BF01464073

Berninger, V. W., Yates, C., Cartwright, A., Rutberg, J., Remy, E., \& Abbot, R. (1992). Lower-level developmental skills in beginning writing. Reading and Writing, 4, 257-280. doi: 10.1007/BF01027151 
Berninger, V. W., Abbott, R. D., Swanson, H. L., Lovitt, D., Trivedi, P., \& Lin, S.-J. (Cindy). (2010). Relationship of word- and sentence- level working memory to reading and writing in second, fourth, and sixth grade. Language, Speech, and Hearing Services in Schools, 41, 179-193. doi: 10.1044/0161-1461\%282009/08-0002\%29

Bialystok, E., Peets, K. F., \& Moreno, S. (2012). Producing bilinguals through immersion education: Development of metalinguistic awareness. Applied Psycholinguistics/First View, 1-15.

Brysbaert, M., \& New, B. (2015). SUBTLEXus. Retrieved from http://www.ugent.be/pp/experimentele-psychologie/en/research/ documents/subtlexus/overview.htm

Carlisle, J. F., Beeman, M., Davis, L. H., \& Spharim, G. (1999). Relationship of metalinguistic capabilities and reading achievement for children who are becoming bilingual. Applied Psycholinguistics, 20, 459-478.

Cumming, A. (1989). Writing expertise and second-language proficiency. Language Learning, 39, 81-135.

Cummins, J. (1984). Language proficiency, bilingualism, and academic achievement. In J. Cummins (Ed.), Bilingualism and special education: Issues in assessment and pedagogy (pp. 136-151). San Diego, C.A.: College Hill.

Davis, L. H., Carlisle, J., \& Beeman, M. (1999). Hispanic children's writing in english and spanish when english is the language of instruction. In T. Shanahan \& F. V. Rodríguez-Brown (Eds.), The 48th Yearbook of the National Reading Conference (pp. 238-248). Chicago.

Durán, L. K., Roseth, C. J., \& Hoffman, P. (2010). An experimental study comparing English-only and transitional bilingual education on Spanish-speaking preschoolers' early literacy development. Early Childhood Research Quarterly, 25, 207-217. doi: 10.1016/j.ecresq.2009.10.002

Edelsky, C. (1982). Writing in a bilingual program: The relation of L1 and L2 texts. TESOL Quarterly, 16, 211-228.

Francis, D. J., Lesaux, N. K., \& August, D. (2006). Language of instruction. In D. August \& T. Shanahan (Eds.), Developing literacy in second language learners: Report of the national literacy panel on language-minority children and youth. Mahwah: N.J.: Lawrence Erlbaum Associates.

Francis, N. (2000). The shared conceptual system and language processing in bilingual children: Findings from literacy assessment in Spanish and Náhuatl. Applied Linguistics, 21, 170-204. doi: 10.1093/applin/21.2.170

Genesee, F., Geva, E., Dressler, C., \& Kamil, M. L. (2006). Synthesis: Cross-linguistic relationships. In D. August \& T. Shanahan (Eds.), Developing literacy in second language learners: Report of the national literacy panel on language-minority children and youth (pp. 365-413). Mahwah, N.J.: Lawrence Erlbaum Associates.

Goldenberg, C. (2008). Teaching English language learners: What the research does- and does not- say. American Educator, 8-44.

Hunt, K. W. (1977). Early blooming and late blooming syntactic structures. In C. R. Cooper \& L. Odell (Eds.), Evaluating writing: Describing, measuring, judging (pp. 91-104). Buffalo, N.Y.: SUNY Buffalo.

Lanauze, M., \& Snow, C. (1989). The relation between first- and second- language writing skills: Evidence from Puerto Rican elementary school children in bilingual programs. Linguistics and Education, 1, 323-339.

McCutchen, D. (1986). Domain knowledge and linguistic knowledge in the development of writing ability. Journal of Memory and Language, 25, 431-444. doi: 10.1016/0749-596X\%2886\%2990036-7

Perfetti, C. A., \& McCutchen, D. (1987). Schooled language competence: Linguistic abilities in reading and writing. In S. Rosenberg (Ed.), Advances in applied psycholinguistics (Vol. 1): Disorders of first-language development (Vol. 2); Reading, writing, and language learning (Vol. 1, pp. 105-141). New York: Cambridge University Press.

Rossell, C., \& Kuder, J. (2005). Meta-murky: A rebuttal to recent meta-analyses of bilingual education. In J. Sohn (Ed.), The effectiveness of bilingual school programs for immigrant children. Retrieved from http://www.bu.edu/polisci/files/2009/09/ Meta-Murky-A-Rebuttal-to-Recent-Meta-Analyses-of-Bilingual-Education.pdf

Schoonen, R., Gelderen, A. van, S., Reinoud D., Hulstijn, J., \& Glopper, K. de. (2011). Modeling the development of L1 and EFL writing proficiency of secondary school students. Language Learning, 61, 31-79. doi: 10.1111/j.1467-9922.2010.00590.x

Slavin, R. E., \& Cheung, A. (2005). A synthesis of research on language of reading instruction for english language learners. Review of Educational Research, 7, 5247-284. doi: 10.3102/00346543075002247

Slavin, R. E., Madden, N., Calderón, M., Chamberlain, A., \& Hennessy, M. (2011). Reading and language outcomes of a multiyear randomized evaluation of transitional bilingual education. Educational Evaluation and Policy Analysis, 33, 47-58. doi: 10.3102/0162373711398127

Thomas, W. P., \& Collier, V. (1997). School effectiveness for language minority students. Washington, D.C.: National Clearinghouse for bilingual Education.

Wilkinson, L. C., \& Silliman, E. R. (2012). Language. In J. Arthur \& A. Peterson (Eds.), The routledge companion to education (pp. 125-135). New York: Routledge. 